\title{
The Impact of High-speed Railway Opening on the Income Gap between Urban and Rural Areas
}

\author{
Hongjie Bao \\ School of Management \\ Northwest Minzu University \\ Lanzhou 730030, China \\ baohongjie88@126.com
}

\author{
Yilong Wang* \\ School of Management \\ Northwest Minzu University \\ Lanzhou 730030, China \\ wyl19881129@163.com \\ *Corresponding author
}

\begin{abstract}
In recent years, the structure of traffic facilities in China has undergone epoch-making changes. As a new type of transportation facility, high-speed railway is convenient, efficient and punctual, which reduces the transaction cost of the regional economy and enlivens the flow of production factors. A new research perspective for narrowing the income gap between urban and rural residents in the region is offered. Based on the economic characteristics of high-speed railway, this work selected data from 30 provinces from 1999 to 2017 . The double difference method (DID) was used to evaluate the impact of highspeed railway opening on the regional income gap between urban and rural residents. It is found that the high-speed railway opening will help to narrow the income gap between urban and rural residents during the investigation period. The further heterogeneity test shows that the high-speed railway opening significantly reduces the income gap between urban and rural residents in the central and western regions. This conclusion offered a useful theoretical support for the implementation of the targeted poverty alleviation policy in China.
\end{abstract}

Keywords-High-speed railway opening; Income gap between urban and rural residents; Population mobility; Policy evaluation

\section{INTRODUCTION}

In recent years, the structure of transportation facilities in China has undergone epoch-making changes. As a new type of transportation facility, high-speed railway has changed the traditional concept of time and space and reduced the cost of production and transaction [1], which promotes the regional economic growth in China. The improvement of transportation infrastructure has greatly reduced the transaction cost caused by the geographical distance, activated the flow of production factors, expanded the boundary of the market and improved the income level of residents. The emergence of high-speed railway has made all sectors of society see a new way to narrow the income gap between urban and rural residents. Relevant research shows that non developed regions can activate the circulation of production factors by means of highspeed railway, thus narrowing the gap between the rich and the poor, and realizing the integrated development of regional economy [2-4]. However, at present, more relevant research has investigated the impact of high-speed railway on regional economic growth. Less attention has been paid to the role of high-speed railway in narrowing the income gap between urban and rural residents, so this work will focus on the study.
The marginal contribution of this work is as follows. Firstly, the high-speed railway opening affects the income gap between urban and rural residents and plays an intermediary role through labor mobility. Compared with the existing modes of transportation, the high-speed operation speed and high convenience of high-speed railway will help to meet the demand that the labor force and other factors flow rapidly in the adjustment and upgrading of industrial structure. It is convenient to investigate the specific path of high-speed railway affecting the income gap between urban and rural residents from a global perspective. Secondly, based on heterogeneity, this work probed into the significant influence of high-speed railway opening in narrowing the income gap between urban and rural residents in different regions. This is beneficial to give full play to the economic value of high-speed railway in narrowing the income gap between urban and rural residents.

\section{LiterAtURE REVIEW AND THEORETICAL HyPOTHESIS}

At present, there are many studies on the economic value of traffic infrastructure and the transformation of economic growth mode, but there are great differences in the research viewpoints. One view is that transportation infrastructure has a significant positive impact on economic growth, increases the income of residents in backward areas [5-6]. Another view is that investment in transport infrastructure has no significant positive impact on economic growth, but increases the income gap [7-8]. As a new type of transportation infrastructure, the literature on improving the income gap between urban and rural residents is rare. Only Chen Fenglong (2018) believes that the positive role of high-speed railway is more inclined to improve the income gap between urban and rural residents in eastern and large urban agglomerations [9].

There are abundant research results on the influencing factors of high-speed railway on the regional economic gap. Compared with the traditional transportation infrastructure, high-speed railway optimizes the traffic efficiency and shortens the time distance between regions. It has greater advantages in carrying passengers, punctuality rate and safety performance, and can better meet the flow of human resources elements [10]. From the perspective of economic accessibility, Jiang Haibing et al discussed the relationship between economic accessibility and time accessibility for different income groups [11]. Based on factor flow, high-speed railway 
improved the quality of regional economic growth by changing the spatial structure, employment structure and industrial structure [12-13]. Therefore, the following assumptions are proposed.

Hypothesis 1: high-speed railway opening narrows the income gap between urban and rural residents in the region.

\section{Model Construction AND VARIABLE SELECTION}

\section{A. Model construction}

By using the double difference method, the economic effect of high-speed railway opening can be evaluated by dealing with the difference between the income gap between urban and rural residents before and after the high-speed railway opening and the change of income gap between urban and rural residents in the control group.

Among them, Eco_gap ${ }_{i t}$ represents the income gap between urban and rural residents of a province $\mathrm{i}$ in the period $\mathrm{t}$ year. treat $_{i t}$ is an individual dummy variable, reflecting that the province value of opening high-speed railway in the t year is 1 , and that of not opening high-speed railway is 0 . post $t_{i t}$ represents the time dummy variable (i.e., the year after opening high-speed railway). Taking 2007 as the policy impact time, the value after 2007 is 1 , whereas the value is 0 . The interaction term treat $_{i t} \times$ post $_{i t}$ represents the processing effect. $X_{i t}$ is the control variable of the model, which controls the related variables that affect the income difference between urban and rural residents. $\varepsilon_{i t}$ is the random error term, and $\mu_{i}$ is the fixed effect term of control province.

\section{B. Variable selection and data description}

\section{1) Variable selection}

The core variable of this work is the income gap between urban and rural residents $\left(E c O_{-} g a p_{i t}\right)$. That is to say, the ratio between per capita disposable income of urban residents and per capita net income of rural residents reflects the income gap between urban and rural residents. The greater the ratio reflects the greater the income difference between urban and rural residents.
The core independent variable of this work is of high-speed railway opening. The virtual variables of whether or not to open high-speed railway in China's provinces from 2005 to 2017 are selected. The interaction term treat $_{i t} \times$ post $_{i t}$ is used as the explanatory variable in this work. Among them, the virtual variable post $_{i t}$ for high-speed railway opening measures the structural change of the income gap between urban and rural residents in the treatment group and control group before and after the high-speed railway opening. The virtual variable treat $_{\text {it }}$ for high-speed railway opening measures the difference of income gap between urban and rural residents in provinces with and without high-speed railway service.

The control variable is the relevant control variable to consider whether to turn on the high-speed railway in this work The economic development level (agdp) is expressed by per capita GDP (logarithm) to alleviate the problem of non-normal distribution. The urbanization level (urban) is expressed by the proportion of urban construction land area in the area under jurisdiction. The opening level (open) is expressed by import and export trade volume / GDP. The education level (edul) is expressed by the number of students (10000) in provincial colleges. The financial development level (finl) is expressed in RMB deposit balance / GDP of financial institutions. The population size (pop) is measured by the number of registered population at the end of the year.

\section{2) Data description}

Although China has carried out the sixth railway speed increase represented by high-speed railway construction since 2007, the Beijing-Tianjin inter-city railway, which opened on August 1, 2008, is internationally recognized as China's first high-speed railway. In order to observe the change of the income gap between urban and rural residents before and after high-speed railway opening, 2005 as the starting point of the research period was chosen. The empirical study in this work selects the panel data of 30 provinces and municipalities in China from 2005 to 2017. At the same time, according to the statistical yearbook, the GDP of each province is reduced. At last, the original data used in the empirical research come from China Urban Statistical Yearbook, China Regional Economic Statistical Yearbook, China Statistical Yearbook, etc.

TABLE I. DESCRIPTION STATISTICS OF MAIN VARIABLES

\begin{tabular}{|c|c|c|c|c|c|}
\hline Variables & Mean value & Standard deviation & Minimum value & Maximum value & Variable declaration \\
\hline Eco_gap & 2.6976 & 0.6283 & 1.2411 & 4.7586 & Income of urban residents / income of rural residents \\
\hline lnagdp & 9.1607 & 1.3051 & 6.3026 & 11.7675 & Per capita GDP logarithm \\
\hline urban & 0.4753 & 0.1609 & 0.2039 & 0.896 & Urban construction land area / district area \\
\hline open & 11.007 & 328.081 & 0.0169 & $1.00 \mathrm{E}+04$ & Import and export trade volume / GDP \\
\hline finl & 1.2309 & 0.6298 & 0.3522 & 5.3778 & RMB deposit balance / GDP \\
\hline edul & 38.5187 & 42.2998 & 0.6 & 199.59 & Number of students in ordinary colleges (10,000) \\
\hline pop & 2507 & 1678.628 & 275.5 & 6766 & Number of household registration population at the end of the year \\
\hline
\end{tabular}

\section{EMPIRICAL RESULTS AND ANALYSIS}

In this work, the double-difference method is used to regression the econometric model expressed in formula (1) by using Stata14 software, and the results are shown in Table 2.
Among them, the model (1) reports the impact of high-speed railway opening on the income gap between urban and rural residents at the national level. Model (2), model (3) and model (4) respectively report the estimated results of the income gap 
between urban and rural residents in the eastern, central and western regions.

TABLE II. REGRESSION RESULTS

\begin{tabular}{|c|c|c|c|c|}
\hline Variables & $(1)$ & $(2)$ & $(3)$ & $(4)$ \\
Eco_gap & Nationwide & Eastern regions & Central regions & Western regions \\
\hline \multirow{2}{*}{ treat×post } & $-0.1879^{* * *}$ & 0.0870 & $-0.2285^{* * *}$ & $-0.3709^{* * *}$ \\
& $(0.0554)$ & $(0.0614)$ & $(0.0787)$ & $(0.0872)$ \\
\hline \multirow{2}{*}{ lnagdp } & $-0.4475^{* * *}$ & -0.0245 & 0.0913 & $0.1503^{*}$ \\
& $(0.0899)$ & $(0.0750)$ & $(0.0856)$ & $(0.0796)$ \\
\hline \multirow{2}{*}{ urban } & $-3.0873^{* * *}$ & $-2.0694^{* * *}$ & $-2.7456^{* * *}$ & $-5.7538^{* * *}$ \\
& $(0.2742)$ & $(0.3206)$ & $(0.5697)$ & $0.7265)$ \\
\hline \multirow{2}{*}{ open } & $0.4086^{* * *}$ & $0.3746^{* * *}$ & 0.1622 & $-1.4260^{* * *}$ \\
& $(0.0477)$ & $(0.0578)$ & $(0.6439)$ & $(0.4127)$ \\
\hline \multirow{2}{*}{ finl } & $0.2665^{* * *}$ & $0.1502^{* * *}$ & $0.5218^{* * *}$ & $0.2075^{* *}$ \\
& $(0.0370)$ & $(0.0310)$ & $(0.0903)$ & $0.0980)$ \\
\hline \multirow{2}{*}{ edul } & $0.0023^{* *}$ & $0.0028^{* * *}$ & 0.0016 & $0.0081^{* * *}$ \\
& $(0.0009)$ & $(0.0010)$ & $(0.0014)$ & $-0.0017)$ \\
\hline \multirow{2}{*}{ pop } & $-0.0001^{* * *}$ & $-0.0001^{* *}$ & -0.0000 & $0.0002^{* * *}$ \\
& $(0.0000)$ & $(0.0000)$ & $(0.0000)$ & $0.3454^{* * *}$ \\
\hline \multirow{2}{*}{ cons } & $8.4754^{* * *}$ & $3.4318^{* * *}$ & $2.3923^{* * *}$ & $(0.5301)$ \\
\hline Individuality & $(0.7484)$ & $(0.6342)$ & $(0.6827)$ & Yes \\
\hline Time & Yes & Yes & Yes & Yes \\
\hline R2 & 0.6330 & Yes & Yes & 0.5879 \\
\hline $\mathrm{N}$ & 511 & 0.3931 & 0.4455 & 187 \\
\hline & & 188 & 136 & \\
\hline
\end{tabular}

The model (1) shows that at the national level, the income gap between urban and rural residents in the provinces where the high-speed railway is opened has narrowed significantly compared with the provinces where the high-speed railway is not open. The results of subregional regression analysis show that, with the exception of the eastern region, the income gap between urban and rural residents opened by high-speed railway in the central and western regions has narrowed significantly. This is basically consistent with the results dealt with at the national level. From the result of the control variable, the higher the urbanization development level will help to narrow the income gap between urban and rural residents, so as to alleviate the widening of the income gap between urban and rural residents.

\section{CONCLUSION AND ENLIGHTENMENT}

Based on the economic characteristics of high-speed railway, this work selected data from 30 provinces from 2005 to 2017. The double-difference method was used to evaluate the impact of high-speed railway opening on the regional income gap between urban and rural residents. It is found that the high-speed railway opening will help to narrow the income gap between urban and rural residents during the investigation period. Further heterogeneity test shows that although the high-speed railway opening has no impact on the income gap between urban and rural residents in the eastern region, it has a significant impact on narrowing the income gap between urban and rural residents in the central and western regions.

Therefore, from the policy level, the construction of highspeed railway in the central and western regions should be further vigorously developed. It is of great value to narrow the income gap between urban and rural areas in the central and western regions and to realize a well-off society in an all-round way. Combined with the current targeted poverty alleviation policy of the central government, relevant functional departments should give priority to the location in the central and western regions in the construction of high-speed railway. The central and western regions are offered corresponding financial and financial support, which give full play to the maximum value of high-speed railway construction. Therefore, the economic development of the central and western regions is promoted, and the income gap between urban and rural areas in the central and western regions is narrowed.

\section{ACKNOWLEDGMENTS}

This work was supported by the Fundamental Research Funds for the Central Universities of Northwest Minzu University Grant No.31920180101);

This work was supported by the Fundamental Research Funds for the Central Universities of Northwest of Northwest Minzu University Grant No.31920190117);

This work was supported by the Fundamental Research Funds for the Central University of Northwest of Northwest Minzu University Grant No.31920190032);

This work was supported by National Social Science Fund Youth Project Grant No.19CGL061).

\section{REFERENCES}

[1] Yin M, Bertolini L, Duan J. The Effects of the High-speed Railway on Urban Development: International Experience and Potential Implications for China. Progress in Planning. 2015, 98: 1-52.

[2] Levinson D M. Economic Development Impacts of High-Speed Rail [J]. Social Science Electronic Publishing. 2010, 22(2): 288-291.

[3] PENG, Bin, XIA, et al. High-Speed Railway: Review on the Regional Impact and Economy Development. Advanced Materials Research, 2011, 213:107-110. 
[9] Chen Fenglong, Xu Kangning, Wang Meichang. High-Speed Railway Development and Urban-Rural Income Inequality: Evidence from Chinese Cities. Economic Review. 2018, 210(2): 59-73.

[10] Du Xingqiang, Peng Miaowei. Do High-speed Trains Motivate the Flow of Corporate Highly Educated Talents? Economic Management. 2017, 564(12): 89-107.

[11] Jiang Haibing, Zhang Wenzhong, Qi Yi, Jiang Jinliang. The Land Accessibility Influenced by China's High-speed Rail Network and Travel Cost. Geographical Research. 2015, (34): 1015-1028.

[12] Dong Yanmei, Zhu Yingming. Can High-Speed Rail Construction Reshape the Layout of China's Economic Space-Based on the Perspective of Regional Heterogeneity of Employment Wage and Economic Growth. China Industrial Economics. 2016, 343(10): 92-108.

[13] Shao S., Tian, Z.H., \& Yang, L.L. High-Speed Rail and Urban Service Industry Agglomeration: Evidence from China's Yangtze River Delta Region. Journal of Transport Geography. Vol. 64, 2017, pp. 174-183. 